\title{
A CONTRIBUIÇÃO DA TEORIA ATOR-REDE PARA AS PESQUISAS EM EDUCAÇÃO
}

Fátima Teresa Braga Branquinho ${ }^{1}$

Fátima Kzam Damaceno de Lacerda ${ }^{2}$ (D)

\begin{abstract}
Resumo
Este artigo busca discutir, à luz da teoria ator-rede - opção teórico-metodológica do campo da antropologia das ciências e das técnicas baseada na etnografia de objetos -, os limites e as possibilidades de pesquisas, em especial, em educação. Para tal, são apresentadas seis noções chave que orientam a realização de investigações de um modo mais democrático, evidenciando, dessa forma, a indissociabilidade entre escolha epistemológica e escolha política. Considera-se que os procedimentos aqui discutidos também podem trazer contribuições significativas no sentido de redesenhar as fronteiras entre humano e nãohumano e de desfazer como absolutas dicotomias como natureza/sociedade, conhecimento científico/conhecimento popular, ciência/arte.
\end{abstract}

Palavras-chave: Rede sociotécnica; Desierarquização dos saberes; Antropologia das ciências e das técnicas; Social, Não-humano

\section{LA CONTRIBUCIÓN DE LA TEORÍA ACTOR-RED PARA LAS INVESTIGACIONES EN EDUCACIÓN}

\begin{abstract}
Resumen
Este artículo trata de discutir, a la luz de la teoria actor-red - opción teórico-metodológica del campo de la antropología de las ciencias y de las técnicas basada en la etnografía de los objetos -, los límites y las posibilidades de investigación, especialmente, en educación. Para

\footnotetext{
${ }^{1}$ Pós-doutorado no Centre de Sociologie de Innovation/École Nationale Supérieur des Mines de Paris e no Núcleo Interdisciplinar de Estudos do Imaginário/CFICH/UFPE. Professora Associada da Faculdade de Educação da Universidade do Estado do Rio de Janeiro (UERJ). E-mail: fatima.branquinho@ uol.com.br

${ }^{2}$ Doutorado em Meio Ambiente (PPGMA/UERJ). Professora Adjunta do Instituto de Química da Universidade do Estado do Rio de Janeiro (UERJ). E-mail: fatima_kzam@yahoo.com.br
} 
este fin, se presentan seis nociones clave que orientan la conducción de investigaciones de una forma más democrática, evidenciando de este modo la inherencia entre elección epistemológica y elección política. Se considera que los procedimientos discutidos aquí pueden también aportar significativas contribuciones al redefinir las fronteras entre humano y no humano y de deshacer como absolutas las dicotomías naturaleza/sociedad, conocimiento científico/conocimiento popular, ciencia/arte.

Palabras clave: Red sociotécnica; Desercarización de los saberes; Antropología de las ciencias y de las técnicas; Social, No humano

\title{
THE CONTRIBUTION OF THE ACTOR-NETWORK THEORY TO RESEARCH IN EDUCATION
}

\begin{abstract}
This article seeks to discuss, in the light of actor-network theory - the theoreticalmethodological option of the field of anthropology of sciences and techniques based on the ethnography of objects - the limits and possibilities of research, especially in education. To this end, six key notions are presented that guide the conduct of investigations in a more democratic way, evidencing in this way the indissociability between epistemological choice and political choice. It is considered that the procedures discussed here can also bring significant contributions in the sense of redrawing the boundaries between human and nonhuman and of undoing as absolute dichotomies such as nature/society, scientific knowledge/popular knowledge, science/art.
\end{abstract}

Keywords: Sociotechnical network; Deserarchization of knowledge; Anthropology of sciences and techniques; Social, Nonhuman

\section{INTRODUÇÃO}


Este trabalho possui como objetivo discutir as contribuições, limites e possibilidades da teoria ator-rede para o desenvolvimento de investigações sobre diferentes temas pertinentes ao campo educacional. $\mathrm{O}$ artigo surge como oportunidade para divulgar a produção intelectual idealizada por um grupo de pesquisa que se dedica a investigar a realidade a partir de referenciais teórico-metodológicos que favorecem o diálogo entre diferentes saberes e ciências. Os participantes encontraram na teoria ator-rede uma possibilidade de compreender realidades complexas e que, portanto, transbordam os limites de campos disciplinares instituídos, adotando procedimentos teórico-metodológicos que se caracterizam por redesenhar as fronteiras entre humano e não-humano; refletir sobre a noção linear do tempo relacionada ao acúmulo de conhecimento; observar a realidade bem devagar e sem categorias prévias; seguir os atores que "fazem-fazer" e imprimem processos/mudanças à realidade estudada. Assim, a teoria ator-rede indica que é preciso ser experimental e buscar perceber que a realidade estudada vai emergindo por meio das mediações e processos identificados ao seguir os atores do cotidiano nas ações que praticam, naquilo que "fazem-fazer". Essa teoria defende, ainda, a noção segundo a qual uma parte da nossa humanidade é feita da inumanidade dos objetos, tal e qual acontece nas sociedades que não têm a ciência como primeira escolha de instrumento de leitura do mundo. A esta possibilidade que tal teoria abre denominamos desierarquização dos saberes. O grupo se sente motivado a problematizar uma questão que é comum a todos: quais são os limites e possibilidades das pesquisas no campo da educação na compreensão das realidades estudadas? Como esse campo de conhecimento se constitui? O que, na dialogia entre saberes que emerge do campo, o torna um campo político de produção de verdades? Qual a abertura para o diálogo com outros saberes na busca de resolução para demandas sociais concretas? Trata-se, assim, de refletir sobre o modo hegemônico de construir conhecimento. Por conseguinte, o trabalho busca discutir, à luz da teoria ator-rede, limites e possibilidades de pesquisas no campo da educação.

É neste contexto que apresentaremos as propostas que emergem da teoria ator-rede para então discorrer sobre as seis noções chave que nos ajudam a fazer pesquisa de um modo mais democrático, evidenciando a indissociabilidade entre escolha epistemológica e escolha política.

\section{O QUE NOS PROPÕE A TEORIA ATOR-REDE?}


A teoria ator-rede (TAR ou ANT) $)^{3}$ - opção teórico-metodológica do campo da antropologia das ciências e das técnicas - busca compreender as relações entre conhecimento e sociedade investigadas à luz de diversas teorias ${ }^{4}$. De acordo com os princípios desse campo, objetos da técnica e da ciência são não-humanos coadjuvantes na construção de itinerários intelectuais, na produção do conhecimento, na transformação da realidade social (LATOUR, 1994). Embora exista um grupo de pesquisadores nas ciências humanas e sociais que considera esse argumento em seus estudos, o interesse pelos objetos não é nem consensual, nem uniforme. Em outras palavras: nas ciências humanas e sociais, os objetos recebem tratamento heterogêneo. Considerá-los atores e, portanto, híbridos de natureza e cultura, traz consequências para o pensamento que busca explicar, compreender e descrever a realidade. Uma das consequências principais é afetar a concepção de ciência que normalmente funciona como propedêutica à elaboração de estratégias de pesquisa. Afinal, para a concepção hegemônica

cabe à ciência a representação dos não-humanos, mas lhe é proibida qualquer possibilidade de apelo à política; cabe à política a representação dos cidadãos, mas lhe é proibida qualquer relação com os não-humanos produzidos e mobilizados pela ciência e pela tecnologia. (LATOUR, 1994, p. 33-34).

Latour (1994) nos ajuda a problematizar tal separação entre sujeito-objeto, entre natureza-sociedade, propondo que tais distinções são construções históricas e culturais, não emergindo naturalmente dos fatos. Para o autor, na realidade, esta separação nunca ocorreu, o que justifica o título de seu ensaio: Jamais fomos modernos. Latour (1994, p. 102) afirma nesse ensaio que "nem bem os modernos separam os humanos de não-humanos, nem bem os outros superpõem totalmente os signos e as coisas". Esta é uma escolha teórico-metodológica que engendra uma postura que é tão epistemológica quanto política.

\footnotetext{
${ }^{3}$ A antropologia das ciências e das técnicas, ou sociologia das associações ou "teoria ator-rede" (Actor Network Theory - ANT) estabelece diálogos entre vários autores, como Callon (1986), Law (1992), Ingold (2000); Stengers (2002); Haraway (2003), entre outros.

${ }^{4}$ Como exemplos de teorias contemporâneas e suas contribuições para o conhecimento da realidade social, podemos citar: a Fenomenologia (SCHUTZ, 1979), a Hermenêutica (PALMER, 1986), o Estruturalismo (LÉVISTRAUSS, 1989a), a Teoria Crítica (FREITAG, 1988), a Teoria Sistêmica (BUCKLEY, 1971), a Sociologia do Conhecimento (BERMAN, 1986), entre outras, cujas problemáticas implicam o diálogo com outras ciências sociais e com a filosofia.
} 
E, por que é política? Se o conhecimento produzido pelas sociedades que têm a ciência como instrumento de leitura do mundo é de mesma natureza que aquele produzido pelas sociedades que não possuem tal instrumento - isto é, se nenhuma delas separa a natureza da cultura - então, não há razão, fundada na epistemologia, que justifique a hierarquia entre os saberes. Esta forma de conceber a ciência - híbrida de natureza e cultura como são outras formas de conhecer - pode fundamentar a escolha por soluções de problemas reais em todos os campos da vida humana, do ambiental ao educacional, da saúde à engenharia e, assim, se traduzir em um modo particular de se conceber ciência, de fazer pesquisa e interagir, a partir dela, com as demandas sociais.

Em resumo, essa concepção de ciência, desse modo de pensar a realidade que considera, por um lado, que objetos são quase-sujeitos, dotados de capacidade de ação, tal como sujeitos são quase-objetos, submetidos que estão às ações de diferentes atores da rede, humanos e nãohumanos, justifica uma disposição não hierárquica entre tais atores e o conhecimento que possuem sobre a realidade. Tal desierarquização dos atores abre caminho para uma postura diplomática e que, por isso, é mais democrática e merece ser discutida e levada em conta no âmbito das pesquisas acadêmicas, em especial, na área da educação.

$\mathrm{O}$ argumento mais poderoso para defesa deste ponto de vista é tornar mais fácil o abandono da noção segundo a qual nos consideramos melhores do que outras sociedades e tribos, apenas porque temos a ciência como instrumento de leitura do mundo. Como Latour (1994) diz,

[...] talvez nos seja mais fácil, hoje, abandonar a crença em nossa própria estranheza. Não somos exóticos, mas sim comuns. O que consequentemente também faz com que os outros deixem de ser exóticos. São como nós, jamais deixaram de ser nossos irmãos. Não devemos acrescentar o crime de nos acreditarmos radicalmente diferentes a todos os outros que já cometemos. (LATOUR, 1994, p. 125).

Afirmar a não hierarquização dos saberes implica, finalmente, na revisão do que é sujeito e do que é objeto. A epistemologia que considera que "vivemos em sociedades que têm por laço social os objetos fabricados em laboratório" (LATOUR, 1994, p. 27) renova a visão de mundo e modos de agir, por defender que estes objetos - quase sujeitos compartilham conosco a fabricação da nossa própria existência (BRANQUINHO e SANTOS, 2007). 
É fim de ciclo para o pensamento unidirecional, segundo o qual a natureza é o lugar das coisas em si, o sujeito é o que age e o objeto é passivo, tal como consagra a concepção hegemônica de ciência. A adoção dessa postura indica, ainda, o fim do sentimento de que somos apartados da natureza, isto é, de que ela é um lugar fora de nós. O espaço que se abre quando essa ideia é abandonada, pode tornar possível rever avaliações e condutas diante dos problemas educacionais e do modo de fazer pesquisa a fim de resolvê-los.

Essa proposta vem atender a demanda de alguns autores preocupados que estão em reunir condições para elaboração de respostas à crise educacional e que vêm enfatizando a necessidade de um ensino menos apolítico (CHASSOT, 2000).

A hipótese de trabalho aqui defendida, pressuposto para a elaboração de pesquisas na área educacional, é a de que não vamos alcançar plenamente a resolução das demandas sociais que se apresentam se não conseguirmos alterar a concepção de sujeito e de objeto que fundamenta tais práticas. Ora, se a prática científica e/ou educativa, apesar das múltiplas dimensões que envolvem, são questões essencialmente políticas, porque comportam visões de mundo e interesses diversificados, é preciso ampliar e consolidar a cultura democrática na sociedade (LIMA, 1999). Nesse ensaio, esse argumento justifica a mescla de autores citados, de campos de conhecimentos distintos. E, por que não a partir do reconhecimento de que a noção de desierarquização dos saberes já está presente no campo?

Acreditamos, portanto, na possibilidade de elaboração de estratégias de pesquisa e produção de conhecimento sobre a realidade que se constituam como práticas participativas, nas quais saberes populares e científicos são considerados saberes de mesma natureza, tal qual apresentado em Branquinho e colaboradores (2010) e Branquinho, Costa e Lacerda (2014). Nesses trabalhos, a etnografia do objeto "cerâmica" permitiu a realização de experiências capazes de aliar a formação docente à formação em pesquisa, contribuindo para a elaboração de oficinas de educação ambiental capazes de promover processos educativos e socioambientais que colaborem com a justiça social a partir da desierarquização dos saberes.

Desta forma, consideramos que as noções de ciência próprias aos estudos sociais das ciências e técnicas (ou antropologia das ciências e das técnicas ou sociologia das associações) contribuem para a implementação de práticas educativas mais democráticas, transformadoras. De acordo com os princípios desse campo, natureza e cultura são consideradas de modo simétrico (LATOUR, 1994) e, assim, objetos da técnica e da ciência são coadjuvantes na 
produção do conhecimento, na transformação da realidade social. A etnografia de objetos revela como estes se associam aos demais atores/mediadores e com o ambiente natural. No estudo realizado com vistas ao entendimento da rede sociotécnica da cerâmica (BRANQUINHO, 2014), a fala de uma das ceramistas entrevistadas na cidade de Vassouras, no Rio de Janeiro, nos indica que o importante não é oferecer respostas prontas para os alunos, é deixar que busquem as suas próprias respostas:

\begin{abstract}
A necessidade do mundo está associada a necessidade delas (crianças). E quanto mais cada um de nós se expressar por meio dessa necessidade, mais rica se tornará a noção de universo, mais fácil de resolvermos nossos problemas. Porque se cada um estiver buscando as soluções para si, com certeza estará encontrando soluções para muitos outros. E fica tudo mais fácil. Enriquecer o mundo é o papel da arte, multiplicar. (Ceramista, Vassouras/RJ, 2014).
\end{abstract}

Essa fala, à luz da teoria ator rede, traduz, em outros termos, as relações entre o local/global, o individual e o coletivo - dilemas próprios às ciências sociais e que são como força motriz da sua produção. A diferença está no fato de que a teoria ator-rede não pretende equacionar esses dilemas, apenas aceitar e lidar com eles, tomando-os em conta no processo de produção de conhecimento de qualquer realidade em estudo. Isso significa dizer que a construção do campo da antropologia das ciências e das técnicas, nas últimas quatro décadas, avançou na compreensão de realidades processuais e múltiplas explicadas pelos atores que estabelecem controvérsias sobre tais explicações. Essas controvérsias desdobram associações entre atores de tempos e espaços diversos, como por exemplo, a cerâmica, que é arte de famílias de tradição indígena ou parte de objetos técnicos sofisticados usadas na prospecção do petróleo ou na fabricação de relógios de última geração.

As limitações da ANT emergem de suas possibilidades, já que haverá sempre um número muito maior de associações não encontradas do que associações descritas. A esse limite os teóricos da ANT chamam de plasma: aquilo que escapou dos fios condutores das redes, o que deixam sem conexão, aquilo que não conectam.

O que sustenta a pesquisa no campo educacional e realização das práticas transformadoras associadas à ela as quais nos referimos? São seis as noções-chave que consideramos e que nos ajudam a pensar como fazer pesquisa, como construir conhecimento sobre a realidade e, especialmente, como agir no sentido de realizar práticas transformadoras. Essas noções-chave têm, portanto, uma dupla função: são procedimentos teórico- 
metodológicos para a produção de conhecimento sobre a realidade e fundamentos para procedimentos docentes em situações de aprendizagem. Para os teóricos da ANT, fazer pesquisa é fazer política (LATOUR, 2012, p. 370).

\section{SOBRE AS SEIS NOÇÕES-CHAVE}

As seis noções chave que nos orientam nas pesquisas estão associadas entre si, não possuindo uma ordenação ${ }^{5}$. Todas são parte de uma mesma postura epistemológica que foi colocada em prática e problematizada nos trabalhos de Branquinho (2007, 2014), Branquinho e colaboradores $(2010,2014)$ e Frade e colaboradores (2016a, 2016b) ao assumirem a tessitura do conhecimento em rede, com todos os atores envolvidos. Fagundes (2017) também nelas se inspira para propor uma epistemologia da educação escolar, sustentando a ideia de que a escola, com seus professores, alunos e demais atores, produzem conhecimento.

\section{1 É possível a desierarquização entre os saberes?}

A primeira noção-chave é a desierarquização de saberes: é possível valer a palavra de todos? Como a teoria ator-rede nos ajudou a pensar sobre isso?

Nas pesquisas realizadas na área de educação, nos nossos projetos de extensão envolvendo a comunidade escolar, pensávamos: o que fazer de tanta sabedoria e conhecimento daqueles com quem trabalhamos - os participantes dos projetos de pesquisa, os professores e estudantes da escola básica, os licenciandos, todos os sujeitos humanos e nãohumanos e sua presença filtrada pelos relatos dos pesquisadores - e que não estão contemplados na academia? Como é possível ignorar seu modo de lidar com a natureza, de cuidar da saúde, de explicar o céu, a terra, o mar? Como, seguindo algum modismo pedagógico, poderíamos considerar a noção segundo a qual educar é partir do conhecimento já vivido para elevar esse patamar de conhecimento sobre a realidade até o conhecimento científico? Por que esse conhecimento sobre as coisas é tão desvalorizado e, até mesmo, alvo de deboche, principalmente, quando dialoga com a transcendência? Deveria haver um nexo,

\footnotetext{
${ }^{5}$ Uma versão do relato destas noções chave encontra-se em Água de moinho: práticas transformadoras em arte e pesquisa, modos de estar com o outro em trocas intensas, de ser fluxo (FRADE et al., 2016a).
} 
uma conexão, uma ponte, algo que possibilitasse contato entre esses dois universos cognitivos - saberes tradicionais e saberes científicos - algo que permitisse a troca entre nós, sem demagogia, algo que permitisse afirmar que vivemos em um mesmo mundo comum!

Quando Levi-Strauss (1989b) escreve O pensamento selvagem afirma que mesmo os grupos que não tem a ciência como instrumento de leitura do mundo, tal como a conhecemos hoje, possuem um conhecimento que tem valor: a ciência do concreto. Afinal, para Strauss (1989b), o processo de classificar está na base de todo pensamento. Mas, alguma coisa de "selvagem" ainda estava presente. Quando Latour (1994) publica Jamais fomos modernos: ensaio de antropologia simétrica, algo ressoa um pouco mais definitivo para construirmos o argumento da desierarquização entre saberes, uma vez que, para o autor, nós também misturamos tudo, tal qual os selvagens, embora pensemos que separamos.

Então, seguindo os passos de Latour (1994), acreditamos que há nexos, conexões, pontes, elementos de travessia que possibilitam contato entre universos cognitivos: promover diálogos entre saberes tradicionais/populares e saberes científicos nos permite afirmar que vivemos em um mesmo mundo comum! Mas, o que de um conjunto de conhecimentos ressoa no outro? Há uma circularidade, como não reconhecer? (BRANQUINHO, 2007). Mas, para além deste reconhecimento e da importância que o conhecimento tradicional tem para alguns setores e espaços da vida de todos - vida acadêmica ou não - ainda é preciso colaborar para a admissão dessa circularidade e importância desse conhecimento não científico na academia. Afinal, quais noções podem ser reunidas, no fazer da pesquisa e da docência, para fortalecer o argumento definitivo sobre o fato das diferenças que existem entre saberes, por si só, não justificarem hierarquização? Esse argumento precisa ser forte, ser sólido e precisa falar a linguagem da ciência, passando por dentro dela, utilizando seus próprios elementos e sua lógica. Tais noções, ao mesmo tempo, estranhas e familiares podem ajudar na compreensão do mundo comum a todos nós, que parece partido, pouco inteligível quando se trata de olhar para redes de saberes que trançam visão de mundo e modos de vida e trabalho.

Com as ferramentas desse referencial teórico, onde se destaca Latour (1994), a teoria ator-rede, que se desdobra sobre o conhecimento em termos completamente práticos, podemos ultrapassar o desconforto interno do que queremos ver transformado: a supremacia de algum tipo de saber sobre outro. 


\subsection{O tempo: linear ou em espiral?}

Uma segunda noção que nos convoca a ser pensada é a noção de tempo. Latour (1994, p. 15) chama a atenção para o fato de que a modernidade possui vários sentidos, várias definições, mas todas elas "apontam, de uma forma ou de outra, para a passagem do tempo". O mundo moderno, então, é marcado pela flecha irreversível do tempo, rompendo com o passado, numa necessidade incontrolável de progresso. Então, para o autor, a reconstituição histórica constitui-se num sintoma da modernidade que, ao datar tudo, guardar tudo, pretende romper definitivamente com seu passado a fim de ter a impressão de que o tempo passa, e que tudo que é arcaico ficou para trás, suplantado pelas revoluções que enterraram ou invisibilizaram os recalques.

Neste contexto, Lacerda (2012), ao se inspirar na teoria ator-rede para problematizar a noção de tempo na discussão sobre a formação de professores na modalidade a distância, relata que a rede de educação a distância brasileira reúne elementos de distintas épocas e complexidades, ou seja, utiliza de forma integrada velhas e novas tecnologias - materiais impressos, computadores, ambientes virtuais de aprendizagem, telefone -, numa verdadeira espiral: tudo tão velho, tudo tão novo. Afinal, como bem aponta Latour (1994, p. 74), “há algum país que não seja uma terra de contrastes?"

Essa mesma ideia está no Almanaque Toda Oficina da Vida, escrito por Nogueira (2008), quando ela nos diz que nem sempre se registrou o tempo como hoje.

Desta forma, a postura epistemológica que rejeita a noção de tempo como seta irreversível - progresso ou decadência - tem uma consequência sobre a pesquisa, sobre o ato de pesquisar e que ressoa na terceira noção chave.

\subsection{A desaceleração da prática de pesquisa}

A terceira noção chave é a desaceleração: observar a realidade bem devagar e sem categorias prévias.

Stengers (2013), no livro "Uma outra ciência é possível”, sugere uma reflexão sobre o tempo da pesquisa, traz a noção de uma desaceleração da ciência, pede para irmos mais devagar, um mais devagar teórico, tal e qual nos lembra Nogueira (2008), na obra já citada, 
sobre a postura do sertanejo, que combina real e imaginário, razão e desrazão, natureza e cultura, em um exercício estranho e contundente de conexão de saberes e interdependência de noções. Seus estudos indicam que é preciso observar mais, perceber mais, hesitar mais ao construirmos um conhecimento sobre a realidade que nos interessa compreender. Essa terceira noção - de desaceleração - não é, assim, apenas temporal. Isso significa dizer que os grupos de pesquisa devem ser experimentais: seus objetivos existem, mas de forma difusa, permitindo que as coisas vão surgindo a partir de observação bastante atenta, intensa. Mol (2005) chama isso de política ontológica: tal política tira o pesquisador do lugar daquele que sabe e ele passa a se sentar no lugar de experimentador, do que não tem pressa, do que não queima etapas, não está preocupado com as metas que tem que atingir; o pesquisador vai para o lugar daquele que não deixa que os fatos o levem tão rapidamente para uma conclusão. Nessa situação, a proposta de verdade científica está à frente, é uma possibilidade, não há garantia de que vai dar certo.

Gostaríamos de enfatizar algo sobre a construção do conhecimento sobre a realidade que defendemos nesse artigo: ter menos certezas, menos hipóteses, antecipar menos os resultados não significa deixar de ser ético ou ser descuidado com a metodologia da pesquisa. Apenas, o que queremos dizer é que o excesso de conhecimento prévio atrapalha a pesquisa. Se antecipamos tudo o que pode ser visto, tiramos o sabor, inviabilizamos a investigação. Por isso, é saudável, para o processo de construção de conhecimento sobre a realidade, não determinar, a priori, como as coisas devem ser. Afinal, esse lugar determinado a priori é um lugar de oposição entre visões de mundo - justo do que nós aqui queremos escapar.

\subsection{O "social" deve explicar ou ser explicado?}

Estas reflexões nos levaram a compreender uma questão que está bem formulada no estudo intitulado Reagregando o Social escrito por Latour (2012). Afinal, o que é "social"? O que significa a palavra "social" quando associada às expressões "fator social", "contexto social", "psicologia social"? Esse "social" explica alguma coisa? No âmbito da teoria atorrede, não. Social é o que precisa ser explicado. Na prática da pesquisa, o que isso significa? Significa abordar o social mais com perguntas/questões do que com categorias prontas (o que 
se relaciona com a terceira noção), um pouco às avessas, um pouco no feminino, como Manoel de Barros (2003, p. 9) faz ao escrever, por exemplo, O Apanhador de Desperdícios.

Então, na prática, qual é a estratégia para compor o social, esse nosso mundo comum e reconhecer os diálogos nas diferenças? A teoria ator-rede, como ferramenta prática, indica que é preciso ser experimental: buscar, observar, e a realidade estudada vai emergindo por meio das mediações e processos que vamos identificando ao seguir os atores do cotidiano, nos processos, nas ações que praticam, naquilo que "fazem-fazer". Portanto, a teoria ator-rede diz "Siga os atores, descreva as associações”. Na verdade, o social deve ser composto à medida que seguimos os atores que fazem-fazer. (LATOUR, 2001, p. 321).

E, nós aprendemos que isso é tão simples quanto difícil e poderoso, pois implica considerar o papel dos não-humanos, considerar que eles têm agências, provocam associações, produzem associações, o que nos leva à quinta noção chave.

\subsection{Há fronteiras entre humanos e não-humanos?}

Afinal, as ciências e as técnicas são plenas de não-humanos imersos em nossa vida comum: do celular, que parece alterar as noções de tempo e espaço, ao satélite que, à distância, mostra algo de nós mesmos. Do dispositivo hospitalar que mantém a vida no limite, ao DNA que indica a paternidade de uma criança (e que o faz no lugar da mãe, antes o ser mais autorizado para indicar quem é esse pai). Trata-se, assim, de uma ferramenta poderosa por fazer pensar que uma parte da nossa humanidade é feita da inumanidade dos objetos, tal e qual acontece nas sociedades que não possuem a ciência como instrumento de leitura do mundo, um pouco na contramão do que sugeriu Levi-Strauss (1989b). Não são os outros - os donos do pensamento selvagem - que se equiparam a nós por terem um tipo de ciência, a ciência do concreto, porque a capacidade de classificar está na base de todo pensamento. Somos nós que, apesar da ciência tentar separar o objeto do sujeito, a natureza da cultura, permanecemos misturando-os.

Considerando que essa interdependência é ontológica, essa noção nos ajuda a pensar um mundo mais democrático. Concordarmos com a noção segundo a qual a possibilidade do fim da guerra no mundo pode estar associada ao fim da guerra de mundos, como a que é travada entre o mundo da Ciência e o mundo dos saberes tradicionais. Quem sabe, não poderemos ir 
substituindo a noção de conflito pela de controvérsia, bem mais lúdica, construtiva e espontânea?

Temos que reconhecer, portanto, que nós - sociedade científica e técnica - tal como as sociedades ditas "primitivas", somos tecidos na heterogeneidade humano-não-humano e, diante dessa noção de interdependência, refazemos a pergunta: o que é humano? O que conta como humano? E o que isso conta na nossa humanidade? Essas são, sim, perguntas que nos ajudam a pensar a composição de um mundo comum a todos, mais democrático. É diante dessa noção de interdependência que afirmamos que as coisas, os objetos nos humanizam ${ }^{6}$.

\subsection{A pesquisa se faz "com" ou "sobre" o outro?}

Há, para nós, mais uma razão para a teoria ator-rede ser tão poderosa para nos ajudar a defender a desierarquização entre saberes. Está presente uma pegada da pesquisa, trazida nos anos 80, por Mol (2005), por Haraway (2003), que é a questão do cuidado. Para Boff (1999, p. 92), o cuidado é "um modo de ser-no-mundo que funda as relações que se estabelecem com todas as coisas". Então, o modo como se constrói o "sentimento do mundo", a pesquisa que se faz pela proximidade, pelo vínculo, e não pelo distanciamento, permite realizar investigações que se faz "com" e não "sobre" o outro. Não é assim tão evidente o que está incluído nesse "com". Do que ele é tecido? É preciso hesitar, ir devagar. E, talvez aceitar mais um convite de Manoel de Barros (1996, p. 73), quando diz no texto Livro sobre nada: "Os outros: o melhor de mim, sou eles!"

Esse enfoque antropológico - o que o Outro mostra de mim? - associado à noção de cuidado, ao pesquisar com e não sobre o Outro, é muito característico de uma percepção que pretende capturar a complexidade, com generosidade, ética, sensibilidade e cuidado com aquilo que se estuda.

Dentre as noções que queremos compartilhar, essa é mais uma, que nos ajuda a construir o argumento sobre a existência do que ressoa do saber tradicional/popular no saber científico e vice-versa, argumento que fortalece a não-hierarquização entre eles, como nos

\footnotetext{
${ }^{6}$ Cf. LATOUR (2012, p. 310).

${ }^{7}$ Expressão utilizada por Alves (2008), tomada de empréstimo do poeta Carlos Drummond de Andrade, para indicar o mergulho com todos os sentidos no que se deseja estudar, superando assim a valorização exacerbada do sentido da visão, preconizada pelo acordo modernista.
} 
propõe, por exemplo, Alves (2010) ao discorrer sobre as razões da pesquisa nos/dos/com os cotidianos e que nos desafia a superar os abismos dualistas de toda ordem.

Desta forma, sugerimos que conversas sobre os limites e possibilidades ${ }^{8}$ da teoria atorrede nas investigações em educação impliquem/motivem ações propositivas de pesquisadores dispostos a considerar como objetos técnicos podem estar constituindo o que denominamos "humano". Trata-se de uma contribuição da sociologia da ciência para a teoria social que tem embasado as pesquisas no campo da educação e em outros campos das ciências humanas e sociais.

\section{PARA NÃO CONCLUIR}

Com esses operadores cognitivos, ou noções chave, confirmamos o que autores de diferentes matizes teóricos dizem sobre o fato da nossa sociedade científica e técnica não se encaixar na dicotomia natureza-sociedade. Praticamos o duvidar das fronteiras e hierarquias, a revisão da noção de tempo, a observação da realidade bem devagar, degustando-a, seguindo os atores que fazem-fazer, sem categorias prévias, - independentemente se são humanos ou não -; ou seja, redesenhando as fronteiras entre humano e não-humano: esses são procedimentos teórico-metodológicos que podem contribuir para desfazer como absolutas outras dicotomias do nosso cotidiano: corpo/alma, natural/sobrenatural, racional/sensível, fato/contexto, popular/cientifico, sagrado/profano, ocidente/oriente, vida/não vida, ciência/arte, e nos ajudar a substituir conflitos, às vezes corporais, por controvérsias, prazerosas conversas.

No fim de tudo, há um grande aprendizado político: aceitamos o convite transgressor de Manoel de Barros (1996, p. 75), quando nos diz que "é preciso transver o mundo". O resultado dessa transgressão diz que faz sentido formular a questão: será que humano em nossa sociedade científica e técnica não pode ser o efeito dessa heterogeneidade? Provisório, inconstante, incerto, indeterminado, híbrido. Será que, assumindo esses procedimentos de pesquisa, não ajudamos a ciência a se reapresentar diferente frente aos outros saberes? Será que isso nos ajuda a construir práticas educativas transformadoras?

Nas experiências formativas aqui mencionadas, as oficinas realizadas se constituíram como estratégia, um meio de compreensão, para o exame da circularidade entre saberes popular e científico sobre a cerâmica e o saber sobre o ambiente a ela associado direta ou

\footnotetext{
${ }^{8}$ Cf. Da dificuldade de ser um ANT: interlúdio na forma de diálogo (LATOUR, 2012, p. 205-226).
} 
indiretamente. As oficinas foram, ainda, ferramentas para a prática docente baseada na noção de rede sociotécnica ${ }^{9}$ e, por isso, prática defensora da não hierarquização dos saberes.

Foi possível verificar que essa concepção de ciência contribui para uma revisão da prática docente, sobretudo no campo da educação ambiental, uma vez que ela implica, igualmente, a indissociabilidade entre cultura e natureza, fatos científicos e valores sociais, conceitos e contextos, sujeitos e objetos, sugerindo a possibilidade de superarmos abismos dualistas originados pela concepção hegemônica de ciência. Vale lembrar que tal concepção hegemônica - que caracteriza as sociedades científicas e técnicas - separa-as das sociedades ditas primitivas, que não têm a ciência como primeira escolha de instrumento de leitura do mundo, estando na base da hierarquização entre os saberes. A noção segundo a qual o conhecimento científico é a verdade sobre a realidade gera postura discriminatória em relação aos saberes dos alunos - saberes populares ou do senso comum - comprometendo o processo de ensino, que segundo Freire (1996, p. 25), é uma relação de troca: “[...] quem ensina aprende ao ensinar e quem aprende ensina ao aprender”. Assim, para que se possa começar a falar, verdadeiramente, em exercício de democracia na escola, é preciso conhecer a natureza do conhecimento científico tal como assumida pela teoria do ator-rede: ele está associado à estrutura social tal e qual nas sociedades não científicas. Para que haja democracia nos processos e nos espaços educativos é necessário mudar esse modelo de ensino baseado na dominação, fragmentação e hierarquização, para um modelo que leve em consideração o outro, a cooperação, a associação e que valorize todos os saberes.

A escolha pela postura epistemológica descrita nesse artigo é eminentemente política. É o frescor trazido pelo resultado das pesquisas realizadas com base nas seis noções chave da teoria ator-rede que pode garantir sua relevância política com a possibilidade da concretização de ações, atendimento de demandas e formulação de políticas em que toda palavra vale, sem hierarquias. Sabemos que trazer esse tipo de narrativa para o espaço acadêmico também é fato político, já que nossos relatos também são desafios, campo de experimentação ${ }^{10}$. O relato científico também reverbera na rede, também é parceria, também é ator. Afinal, isso que chamamos de mundo são versões, a pesquisa também produz mundos! Vamos produzir o nosso, um mundo mais que plural, comum, desierarquizado.

\footnotetext{
${ }^{9}$ Rede sociotécnica é entendida aqui como lócus de produção do conhecimento.

${ }^{10}$ Como bem aponta Latour (2012, p. 214), "Redigir textos tem tudo a ver com método".
} 


\section{REFERÊNCIAS}

ALVES, N. Decifrando o pergaminho: os cotidianos das escolas nas lógicas das redes cotidianas. In: OLIVEIRA, I.B.; ALVES, N. (Org.). Pesquisa nos/dos/com os cotidianos das escolas. Petrópolis/RJ: DP et Alii, 2008. p. 15-38.

. Sobre as razões das pesquisas nos/dos/com os cotidianos. In: Garcia, R.L. (Org.). Diálogos cotidianos. Petrópolis/RJ: DP et Alii/FAPERJ, 2010. p. 67-82.

BARROS, M. Livro sobre nada. Rio de Janeiro: Record, 1996.

BARROS, M. Memórias Inventadas: a Infância. São Paulo: Planeta, 2003.

BERMAN, M. Tudo que é sólido desmancha no ar. São Paulo: Companhia das Letras, 1986.

BOFF, L. Saber cuidar: ética do humano - compaixão pela terra. Petrópolis, RJ: Vozes, 1999.

BRANQUINHO, F.T.B. O poder das ervas nos saberes popular e científico. Rio de Janeiro: MAUAD X, 2007.

BRANQUINHO, F.T.B. Educação ambiental e rede sociotécnica: escolas sustentáveis na construção da sociedade e da natureza fluminenses. Relatório de Projeto de Pesquisa, Universidade do Estado do Rio de Janeiro, não publicado. 2014.

; SANTOS, J.S. Antropologia da Ciência, Educação Ambiental e Agenda 21 local. In: Educação e Realidade, Porto Alegre, Universidade Federal do Rio Grande do Sul, v. 32, n. 1, p. 109-122, jan./jun. 2007.

; SIRENA, M.L.; MACHADO, L.; CASTRO, R.C. Etnografia de objetos e a (des)hierarquização dos saberes: um caminho para a prática docente. Revista Diálogos, Brasília, v. 14, n.1, p. 42-52, 2010. Disponível em: <https://portalrevistas.ucb.br/index.php/RDL/article/view/2927/1837>. Acesso em: 27 maio 2017.

; COSTA, R.P.; LACERDA, F.K.D. Researching on Ceramists from the State of Rio de Janeiro and Thinking Education to Democracy under the View-Point of Actor Network Theory. British Journal of Education, Society \& Behavioural Science, v. 4, n. 1, p. 10-18, 2014. Disponível em:

<http://www.journalrepository.org/media/journals/BJESBS_21/2013/Oct/Branquinho412013 BJESBS5786_1.pdf>. Acesso em: 27 maio 2017.

BUCKLEY, W. A Sociologia e a Moderna Teoria dos Sistemas. São Paulo: Editora Cultrix, 1971.

CALLON, M. The Sociology of an-actor-network: the case of electric vehicle. In: CALLON, M.; LAW, J.; RIP, A. (Ed.). Mapping the dynamics os science and technology. Sociology of science in the real world. London: The Macmillian Press, 1986. 
CHASSOT, A.I. Alfabetização científica: questões e desafios para a educação. Ijuí: Ed. UNIJUÍ, 2000.

FAGUNDES, T.B. Para uma epistemologia da educação escolar. 2017. 187f. Tese (Doutorado em Educação) - Universidade do Estado do Rio de Janeiro, Rio de Janeiro.

FRADE, I.N.; BRANQUINHO, F.T.B.; LACERDA, F.K.D.; ALVES, D. Água de moinho: práticas transformadoras em arte e pesquisa, modos de estar com o outro em trocas intensas, de ser fluxo. Revista Apotheke, Santa Catarina, v.2, n.2, 2016. p. 246-267. 2016a. Disponível em: <http://www.revistas.udesc.br/index.php/APOTHEKE/article/view/7478/5009>. Acesso em: 27 maio 2017.

; BRANQUINHO, F.T.B.; LACERDA, F.K.D.; ALVES, D. Experiências do Saber em Arte e Ciência - Espaços Verdejantes e Formas Comunais. In: ENCONTRO DA ASSOCIAÇÃO NACIONAL DE PESQUISADORES EM ARTES PLÁSTICAS, 25., 2016, Porto Alegre, RS. Anais... Porto Alegre: ANPAP, 26-30, set. 2016. p. 2932-2946. 2016b. Disponível em: <http://anpap.org.br/anais/2016/simposios/s6/isabela_fradefatima_branquinho-fatima_kzam-daniele_alves.pdf>. Acesso em: 27 maio 2017.

FREIRE, P. Pedagogia da autonomia: saberes necessários à prática educativa. 13. ed. Rio de Janeiro: Paz e Terra, 1996.

FREITAG, B. A Teoria Crítica: ontem e hoje. São Paulo: Editora Brasiliense, 1988.

HARAWAY, D.J. The companion species manifesto: dogs, people and significant otherness. Chicago: III Bristol Paradigm, University Presses Marketing, 2003.

INGOLD, T. The perpection of the environmental: essays in livelihood, dwelling and skill. London and New York: Routledge, 2000.

LACERDA, F.K.D. Contribuições da Educação a Distância para a Educação Ambiental: utilização da rede sociotécnica na análise das concepções de meio ambiente e saúde no Polo de Nova Friburgo. 2012. 292 f. Tese (Doutorado em Meio Ambiente) - Universidade do Estado do Rio de Janeiro, Rio de Janeiro.

LATOUR, B. Jamais fomos modernos: ensaio de antropologia simétrica. Rio de Janeiro: Editora 34, 1994.

. A esperança de Pandora: ensaios sobre a realidade dos estudos científicos. Bauru, SP: EDUSC, 2001.

. Reagregando o social: uma contribuição à teoria ator-rede. Salvador: Edufba, 2012.

LAW, J. Notes on the theory of the actor network: ordering, strategy and heterogeneity. Systems Practice, v. 5, n. 4, 1992. p. 379-393.

LEVI-STRAUSS, C. Antropologia estrutural. Rio de Janeiro: Edições Tempo Brasileiro, 1989a. 
O pensamento selvagem. Campinas, SP: Papirus, 1989b.

LIMA, G.F.C. Questão ambiental e educação: contribuições para o debate. Ambiente e Sociedade, ano II, n. 5, p.135-153, 1999.

MOL, A. The body multiple: ontology in medical practice. Duham and London: Duke University Press; 2005.

NOGUEIRA, M.A.L. Almanaque: toda oficina da vida. Recife: Fundação de Cultura da Cidade do Recife, 2008.

PALMER, R.E. Hermenêutica. Lisboa: Edições 70, 1986.

SCHUTZ, A. Fenomenologia e relações sociais. Rio de Janeiro: Zahar Editoras, 1979.

STENGERS, I. A invenção das ciências modernas. São Paulo: Editora 34, 2002.

Une autre science est possible! Empêcheurs de penser en rond/La Découverte, 2013.

Data de recebimento: $18 / 07 / 2017$

Data de aceite: $30 / 10 / 2017$ 